DOSSIÊ

\title{
Trabalhadoras domésticas no Brasil: sujeitos ou sujeitadas na classe, no gênero e na raça?
}

women domestic workers in Brazil: subjects or subjected to class. gender and race?

\section{Mary garcia castio*}

Foto: José Cruz/ Agência Brasil

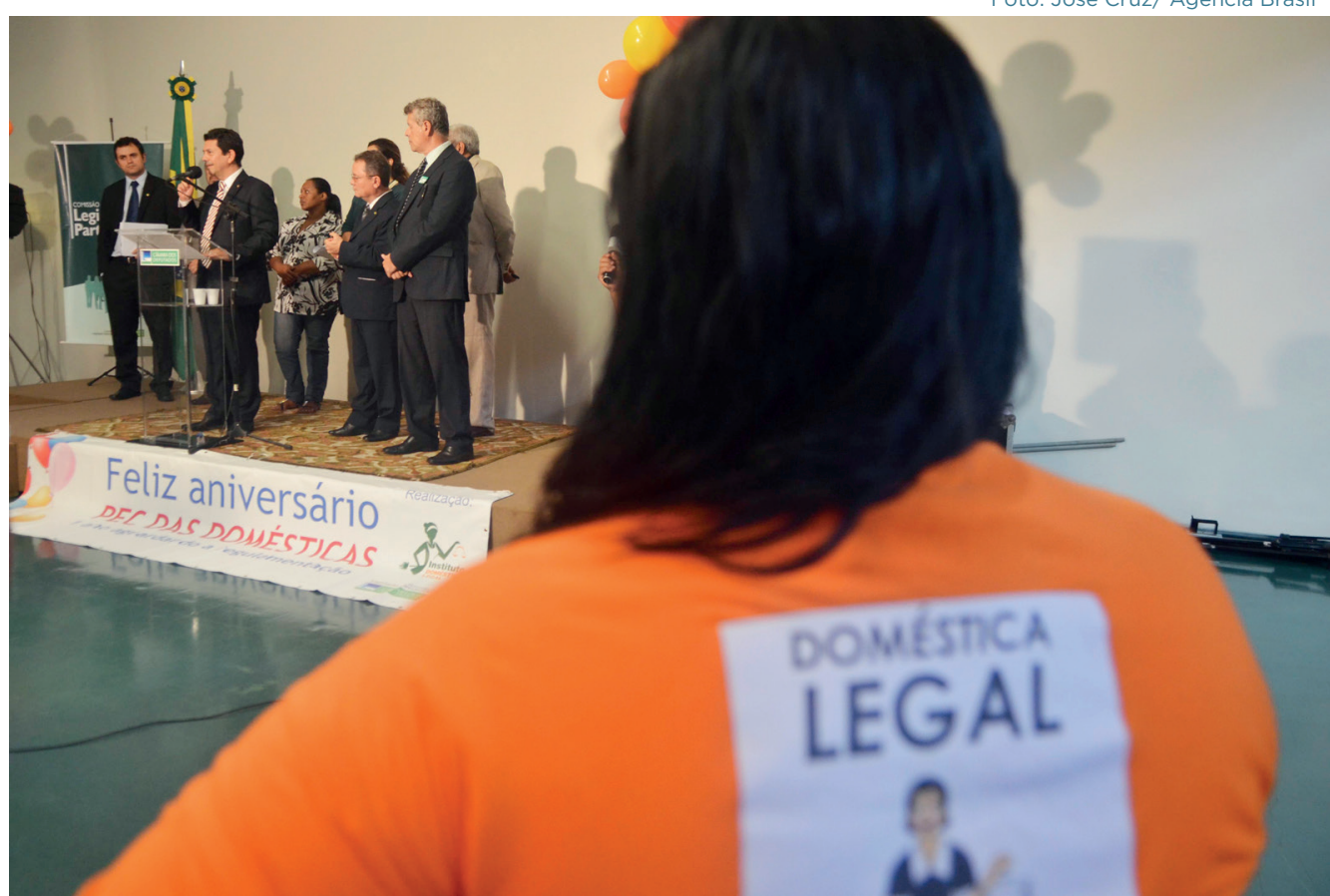

Brasília, DF - 02/04/2014 - Comissão de Legislação Participativa promove ato público para celebrar um ano da promulgação da PEC das Domésticas e alertar para pontos importantes que faltam ser regulamentados 


\section{RESUMO}

Revisitamos escritos sobre trabalhadoras domésticas, com ênfase em seu processo de organização sindical. Ressalta-se o interesse das sindicalistas em ser reconhecidas como parte da classe trabalhadora. Classe que cada vez mais descola subjetividades de experiências vividas em entrelaçamentos de diferentes processos sociais, como gênero e raça. Classe diversificada em termos de composição social e lugar histórico na formação capitalista. Um debate clássico sobre o trabalho doméstico no campo feminista marxista é acessado, e apresentam-se dados sobre o perfil das "domésticas" no Brasil de hoje e como elas estão afirmando resistências nestes tempos de pandemia e barbárie. Palavras-chave: Plataformização da economia; Trabalho; Emprego; Direito do trabalho.

Palavras-chave: Trabalho doméstico; Classe; Gênero; Raça; Sindicato.

\section{ABSTRACT}

We revisit writings on women domestic workers, emphasizing on their union organization process. The interest of the trade union member in being recognized as part of the working class is highlighted. A class that peels more and more subjectivity off of personal experiences into interweaving of different social processes, such as gender and race. A class that is diverse in its social composition and historical place in capitalist formation. A classic debate about domestic work in the feminist Marxist field is accessed and we present data on the profile of domésticas in Brazil today, and how they are resisting in these pandemic and barbaric times.

Keywords: Domestic work; Class; Gender; Race; Labor union.

\section{INTRODUCÃA}

Revisitam-se, neste artigo, escritos sobre trabalhadoras domésticas, com ênfase em seu processo de organização sindical, sublinhando o interesse das sindicalistas em ser reconhecidas como parte da classe trabalhadora. Classe que cada vez mais descola subjetividades de vivências e entrelaces de distintos processos sociais, como os de gênero e raça. Classe que se diversifica em termos de composição social e lugar histórico na formação capitalista.

No primeiro capítulo acessa-se um debate clássico sobre o trabalho doméstico no campo feminista marxista, chamando a atenção para o contemporâneo destaque dado à relação entre gênero e reprodução social.

Seguem-se referências a alguns autores que, por perspectivas marxista, feminista e decolonial, argumentam sobre a singularidade do trabalho doméstico organizado, e como este entrelaça gênero, raça e classe sem se perder em identitarismos, mas forjando um sujeito híbrido. 


\section{Na tentativa de adequar a análise da peculiar situação das mulheres na esfera doméstica às categorias econômicas marxistas, inúmeros autores, principalmente a partir da década de 1960, produziram reflexões teóricas com o objetivo de evidenciar a importância da opressão feminina para o funcionamento do sistema como um todo}

No terceiro capítulo, apresentam-se dados sobre o perfil das "domésticas" no Brasil hoje, segundo distintas dimensões, chamando a atenção para vulnerabilizações em especial das diaristas, e como elas vêm afirmando resistências em tempos de pandemia e barbárie.

O capítulo anterior às considerações finais focaliza a sindicalização das trabalhadoras domésticas, suas resistências a estes tempos de perda de direitos dos trabalhadores e de retrocessos em conquistas, e como elas vêm enfrentando a pandemia de coronavírus.

\section{O TRABALHO DOMÉSTICO: DEBATES FEMINISTAS MARXISTAS}

O trabalho doméstico há muito é tema de debates entre feministas marxistas, sendo que, para muitos autores do campo, ele não teria sido apreciado nas considerações originais de Marx e Engels sobre valor e reprodução da força de trabalho, enquadrando-se como improdutivo ou de esfera pouco sublinhada, a reprodução. Afirmam que seria o trabalho doméstico básico para a produção e reprodução tanto da força de trabalho como da própria vida e sua representação ideológica, haja vista o papel das mães na socialização das crianças. Entre autores que enfatizam a importância da reprodução, historicamente, para a acumulação capitalista, vêm se destacando feministas de perspectivas decoloniais ${ }^{1}$ como Federici (20I7; 20I9). Segundo Federici (20I7, p. I2):

Os três tomos de $O$ Capital foram escritos como se as atividades diárias que sustentam a reprodução da força de trabalho fossem de pouca importância para a classe capitalista, e como se os trabalhadores se reproduzissem no capitalismo simplesmente consumindo os bens comprados com o salário. Tais suposições ignoram não só o trabalho das mulheres na preparação desses bens de consumo, mas o fato de que muitos dos bens consumidos pelos trabalhadores industriais — como açúcar, café e algodão — foram produzidos pelo trabalho escravo empregado, por exemplo, nas plantações de cana brasileiras.

Sobre perspectivas feministas decoloniais, ver, entre outros, Hollanda (2020). 
Interpretam outros autores que em escritos marxistas o trabalho doméstico seria considerado improdutivo e deveria desaparecer, ainda no avanço do capitalismo, contudo não se marginalizaria neles a reprodução ${ }^{2}$.

A caracterização do trabalho doméstico como improdutivo motivou uma série de críticas por parte de feministas contemporâneas, que atribuem a Marx uma visão "misógina", que tenderia a menosprezar a importância da contribuição do trabalho doméstico feminino para a produção social. Na tentativa de adequar a análise da peculiar situação das mulheres na esfera doméstica às categorias econômicas marxistas, inúmeros autores, principalmente a partir da década de 1960, produziram reflexões teóricas com o objetivo de evidenciar a importância da opressão feminina para o funcionamento do sistema como um todo. Note-se que hoje se destaca a centralidade do debate sobre o trabalho doméstico para uma agenda feminista anticapitalista que se pretende crítica à dinâmica de relações pautadas por "classismos", gênero patriarcal e racismo.

Anunciamos debates sobre o trabalho doméstico no sentido de alertar para a importância dos temas trabalho doméstico não remunerado e remunerado, em perspectiva marxista e para a inclusão de sujeitos diversificados, como as trabalhadoras domésticas assalariadas e diaristas, em reflexões sobre informalidade, precariedade, consubstancialidade entre raça, gênero e classe (KERGOAT, 20I0) ${ }^{4}$ e sobre formas consideradas permanências coloniais, mas importantes para o capitalismo.

2 Segundo Andrade (2015):

É certo que a distinção entre os dois tipos de produção indispensáveis a toda ordem social, apontada por Engels no prefácio ao seu livro de 1884, isto é, a dimensão da produção dos meios de subsistência e necessidades sociais e a da produção dos próprios seres humanos, não foi objeto de maior elaboração por parte dos fundadores do materialismo histórico. Os escritos de Marx, particularmente O Capital, não visavam a uma teoria geral da reprodução, abordando a questão a partir da análise histórica das relações sociais desenvolvidas no âmbito do modo de produção capitalista. Contudo, deve-se atentar para o fato de que, de acordo com Marx, produção e reprodução (lato sensu) da ordem social são processos inter-relacionados, que não podem ser concebidos como momentos isolados. O processo de produção, portanto, é considerado "em sua permanente conexão e constante fluxo de sua renovação", de modo que todo processo social de produção é, ao mesmo tempo, um processo de reprodução (MARX, 1985, p. 153 [apud ANDRADE, 2015]). Sob o capitalismo, tal continuidade exigiria o permanente consumo da força de trabalho pelo capitalista e a renovação das condições de exploração do trabalhador - que o obrigam a constantemente vender sua força de trabalho para viver (MARX, 1985, p. 153 [apud ANDRADE, 2015]).

Na realidade, o trabalhador pertence ao capital antes que se venda ao capitalista. Sua servidão econômica é, ao mesmo tempo, mediada e escondida pela renovação periódica da venda de si mesmo, pela troca de seus patrões individuais e pela oscilação do preço de mercado do trabalho. O processo de produção capitalista, considerado como um todo articulado ou como processo de reprodução, produz, por conseguinte, não apenas a mercadoria, não apenas a maisvalia, mas produz e reproduz a própria relação capital, de um lado o capitalista, do outro o trabalhador assalariado (MARX, 1985, p. 161 [apud ANDRADE, 2015]).

3 Sobre as diversas correntes feministas anticapitalistas de hoje, com forte inscrição no marxismo e que elaboram a equação "classe, gênero e raça", ver, entre outros, Castro (2020).

4 O termo consubstancialidade entre classe, gênero e raça é usado por Kergoat (2010) por criticar como autores, em especial relacionados a correntes do feminismo negro, discutem a "interseção" dessas categorias: "Kergoat (2010) é crítica do comum apelo funcionalista na armação de tal trilogia, não se dando conta da singularidade de cada categoria como processo histórico, inclusive com clivagens entre si, e pelo fato de em muitas análises serem usadas como posições individualizadas na sociedade, quando mais ênfase é dada a raça e a gênero, minimizando classe como sistema." (CASTRO, 2020, p. 141). 
Tais reflexões são importantes para melhor compreender a organização e as agendas dos sindicatos de trabalho doméstico remunerado. Aliás, por muito tempo rejeitados por sindicatos de outras categorias, porque as trabalhadoras domésticas não seriam consideradas parte da classe operária, trabalhando em "casas de família" (ver CASTRO et al., 20I8).

Na década de 1970, período de consolidação do movimento feminista em diversos países, tem-se um debate célebre sobre a identidade política do trabalho doméstico na revista New Left Review, que, ainda que não o primeiro ou único, contribuiu para que artigos de Wally Seccombe, por frisar a importância do trabalho doméstico para a reprodução da força de trabalho, sejam até o presente considerados clássicos.

Seccombe, recorrendo a $O$ Capital, argumenta que em Marx o consumo de meios de subsistência pelo trabalhador e a reprodução da força de trabalho foram considerados partes do mesmo processo (SECCOMBE, I974, p. 4 apud MENDES, 20I7, p. 32), o que seria obscurecido no caso do trabalho doméstico, no modo capitalista de produção, por uma separação entre a unidade doméstica e a unidade industrial, já que a dona de casa não mantém relação direta com o capital (SECCOMBE, I974, p. 7 apud MENDES, 20I7, p 34).

Seccombe defende o valor dos bens produzidos pelo trabalho doméstico, que colaboram para o valor da força de trabalho que se emprega na produção de riquezas, como cozinhar, lavar roupas e cuidar das crianças, da casa e do operário. Seriam, portanto, necessários à reprodução da força de trabalho, mas não considerados no plano da teoria do valor:

Para Seccombe, esse trabalho adicional realizado no interior dos lares se cristalizaria na mercadoria força de trabalho a ser vendida no mercado, produzindo, portanto, valor. $O$ fato de esse trabalho ser realizado em espaço privado, ou seja, sem possibilidade de socialização, seria irrelevante: como outros trabalhos realizados fora de relações capitalistas de produção, o fato de ter seu produto vendido em um mercado capitalista abstrairia suas origens e daria a esse trabalho a característica de trabalho humano abstrato. Assim, o trabalho doméstico no capitalismo seria caracterizado por uma dualidade específica: apesar de produzir mercadoria, não teria relação com o capital, portanto, não seria regido pela lei do valor e não poderia produzir mais-valia (MENDES, 20I7, p. 34).

Seccombe (I974 apud MENDES, 2017) também argumenta que parte da mais-valia estaria embasada no trabalho doméstico, em seu valor de uso não pago, importante para a reprodução da força de trabalho. E ressalta que o isolamento da dona de casa no lar dificultaria a ela perceber sua condição de opressão como membro "não trabalhador" da classe trabalhadora, transferindo para as relações sociais na família, com o cônjuge, conflitos que deveriam ser dirigidos contra o capital. Daí ser importante que as mulheres se engajem na vida pública, livrando-se do espaço privado. 


\section{Os debates sobre o trabalho doméstico não} remunerado e o remunerado voltam com força nos escritos contemporâneos de um feminismo marxista crítico, advogando-se a importância do trabalho de cuidados das mulheres para a reprodução inclusive ampliada do sistema, e como tal trabalho, por envolver também a reprodução da vida, seria objeto de controle de corpos femininos pela Igreja e pelo Estado, em particular os racializados

"Isso as colocaria diretamente na arena de disputa política e levaria inclusive a uma divisão mais igualitária o trabalho no interior dos lares” (SECCOMBE, I974, p. 22 apud MENDES, 20I7, p 35).

Coulson, Magas e Wainwright apresentam na revista uma resposta crítica ao artigo de Seccombe, afirmando que o autor teria mais se preocupado com o enquadramento teórico do trabalho doméstico na ordem produtiva capitalista que com a "essencial questão da opressão da mulher". Também argumentam que haveria que mais considerar a dupla jornada, ou seja, os exercícios acumulados do trabalho em casa, como donas de casa, e do público, como trabalhadoras assalariadas (COULSON et al., 1975, p. 60). Consideram que as divisões sexuais do trabalho, e por aí as hierarquizações, não se dariam tão somente no âmbito da família, mas também no mercado. Defendem, contrariamente a Seccombe, a posição de que o trabalho doméstico não cria valor. Apresentam os seguintes argumentos:

I) O produto imediato do trabalho doméstico seriam valores de uso para consumo, e não a mercadoria força de trabalho diretamente (conforme argumenta Seccombe) ou qualquer mercadoria direcionada para o mercado (COULSON et al., p. 62).

2) Como a dona de casa não vende sua força de trabalho no mercado, seria inadequada a sua comparação com um trabalhador improdutivo qualquer para argumentar que ela também produz valor;

3) $O$ trabalho doméstico de fato contribuiria para a produção da mercadoria força de trabalho do trabalhador. O que mediaria a relação desse trabalho com o restante do produto social, entretanto, seria o contrato de casamento e não o mercado, não podendo as condições privadas de sua produção, portan- 
to, serem abstraídas. Só a troca no mercado, em uma economia capitalista, teria a capacidade de permitir a equivalência entre diversos tipos de trabalho concreto em trabalho abstrato (COULSON et al., p. 63).

Dessa forma, o conceito de trabalho abstrato não poderia se aplicar ao trabalho doméstico. [...] Ou seja: a opressão feminina teria raízes outras que não a exploração capitalista, e suas especificidades só podem ser compreendidas, de acordo com as autoras, fora do arcabouço da teoria do valor trabalho (MENDES, 20I7, p. 37).

Coulson et al. (I975, p. 69) defendem a socialização do trabalho doméstico como agenda de um programa socialista para libertar as mulheres de sua "escravidão doméstica”, assim como a organização autônoma das mulheres por suas próprias pautas, o que seria pré-condição para o avanço das lutas sociais.

Note-se que a posição por tirar a mulher da domesticidade do privado já fora defendida por August Bebel, um dos principais líderes da social-democracia alemã, em seu livro A mulher sob o socialismo, de I879,

Onde anuncia abertamente ser "um absurdo direcionar a mulher para a vida doméstica" (BEBEL, 1923, p. I76) e prescreve a necessidade da completa igualdade de oportunidades entre homens e mulheres, de modo que estas passem a compartilhar da vida pública e das questões políticas e sociais, retirando-se do confinamento do lar. O fim da "escravização doméstica" só seria atingido na futura sociedade.

A vida social no futuro será cada vez mais pública. [...] A vida doméstica será restrita ao que é absolutamente necessário, enquanto será aberto um vasto campo para a satisfação dos instintos sociais. Espaços para reuniões, assembleias e discussões públicas sobre questões sociais, locais públicos para brincadeiras, leituras e refeições, bibliotecas, salas de concerto e teatros, museus e ginásios esportivos, parques, jardins, casas de banho, instituições educacionais de todo tipo, laboratórios etc.; tudo isso organizado e equipado da melhor forma possível oferecerá ricas oportunidades para todos os tipos de convívio e para o avanço da arte e da ciência (BEBEL, 1923, p. 332).

Seccombe (1975) apresenta uma réplica às críticas de Coulson et al. ao seu primeiro artigo. "Considera positiva a ênfase dada pelas autoras à relação entre a libertação feminina e a revolução socialista e à dupla jornada de trabalho das mulheres" (MENDES, 20I7, p. 42). Mas insiste na tese de que o trabalho doméstico pode ser analisado segundo a lei do valor. Defende a tese de que de fato o trabalho doméstico não criaria mercadorias, mas valores de uso, porém que haveria equivalência entre esses. Sustenta também que a "existência de salário não seria critério para se afirmar se um trabalho cria valor", e que a maneira como as trocas de trabalho ocorrem dentro da família seria irrelevante para a constatação de que o trabalho doméstico cria valor. $\mathrm{O}$ 
que permitiria a abstração do trabalho doméstico privado, segundo o autor, seria a troca da força de trabalho no mercado, relação que ocorre em esfera externa e independentemente do contrato de casamento, seja ele formal ou não.

Elaborações sobre o trabalho doméstico e o marxismo não se resumem aos termos da polêmica registrada na New Left Review, sendo que outras autoras insistem na necessidade de sair do que consideram o "economicismo" da intelectualidade marxista do século XX (por exemplo, MITCHELL, I966 apud MENDES, 20I7) e dos autores no debate na revista New Left Review (MILES, I983; RUBIN, I993 apud MENDES, 20I7): "explicar a utilidade das mulheres para o capitalismo é uma coisa; afirmar que essa utilidade explica a gênese da opressão da mulher é outra bastante diferente" (RUBIN, I993, p. 4 apud MENDES, 20I7) ${ }^{5}$

Há também controvérsias sobre se o debate quanto ao trabalho doméstico não remunerado colaboraria para melhor se entender o serviço doméstico, ou seja, o trabalho doméstico remunerado e seu lugar na estrutura de classe. Para Albarracín (1999): "As mulheres não elaboram a comida diária para trocá-la no mercado e, caso assim fosse, não estaríamos falando de trabalho doméstico, mas de uma atividade mercantil." Mas se reconhece que mesmo o trabalho doméstico remunerado não se ajusta às análises sobre os demais trabalhos, considerando formulações clássicas no marxismo:

Quanto à empregada doméstica propriamente dita, que recebe um salário do empregador doméstico (uma família que a contrata), faz-se presente o valor. Temos aí uma relação de tipo $\mathrm{M}-\mathrm{D}-\mathrm{M}$, pois a trabalhadora não persegue o lucro, não aplica capital. O que ela faz é oferecer uma mercadoria (seus serviços de lavar, passar, cozinhar etc.) em troca de dinheiro, para então, com ele, adquirir meios de subsistência. Sem a existência de lucro na relação imediata entre ela e a família contratante, a circulação é simples, e não capitalista. Não obstante, veremos que, assim como no exemplo da mulher que trabalha gratuitamente para a própria família, este trabalho colabora para a mais-valia por um caminho tortuoso (CORREIA; BIONDI, 20II).

Ninguém obtém mais-valia do trabalho de uma dada mulher em sua casa, mas o conjunto do sistema pode aumentar a massa total de mais-valia graças ao trabalho doméstico do conjunto de todas as mulheres. Assim, o trabalho doméstico não é regulado pela lei do valor, mas, como ocorre com quase todas as coisas sob o modo de produção capitalista, ele não é independente dela (ALBARRACÍN, 1999, p. 57).

5 Alguns autores que nas décadas de 1970 e 1980 discutiram a relação do marxismo com o trabalho doméstico além dos comentados neste artigo: HIMMELWEIT, Susan. The discovery of "unpaid work": the social consequences of the expansion of "work". Feminist Economics, Londres, v. 1, n. 2, p. 1-19, 1995; ___. Trabalho doméstico. In: BOTTOMORE, Tom (Ed.). Dicionário do pensamento marxista. Rio de Janeiro: Jorge Zahar, 2001; MILES, Angela. Economism and feminism: hidden in the household — a comment on the domestic labour debate. Studies in Political Economy, Londres, v. 11, n. 1, p. 197-209, 1983; MITCHELL, Juliet. Women: the longest revolution. New Left Review, Londres, n. 40, p. 11, 1966. 
Os debates sobre o trabalho doméstico não remunerado e o remunerado voltam com força nos escritos contemporâneos de um feminismo marxista crítico, advogando-se a importância do trabalho de cuidados das mulheres para a reprodução inclusive ampliada do sistema, e como tal trabalho, por envolver também a reprodução da vida, seria objeto de controle de corpos femininos pela Igreja e pelo Estado, em particular os racializados (ver FEDERICI, 2017; 2019 e autoras que abordam perspectivas decoloniais, como HOLLANDA, 2020).

$\mathrm{Na}$ América Latina o serviço doméstico é tema que vem sendo destacado na perspectiva sobre colonialidade do poder - termo cunhado por Aníbal Quijano desde I992, segundo Cahen (20I8), que ressalta a raça como elemento estruturante do processo de modernidade - , e sobre decolonialidades, ou formas de resistências dos subalternizados, historicamente, nas relações entre colonizadores e povos originais ou escravizados, muitas sobreviventes ou remodeladas. Assim se refere Cahen (2018, p. 43-45) ao entendimento sobre colonialidade em Aníbal Quijano:

Por definição, os estudos em termos de colonialidade incidem indissociavelmente sobre as heranças e a reprodução de traços estruturais coloniais no âmbito do sistema-mundo ao longo dos séculos até hoje. Essas estruturas são coloniais, isto é, não diretamente moldadas pelo modo de produção capitalista - como é o caso da matriz racial, constitutiva do mundo moderno e que existe bem antes deste modo de produção - mas são estruturas das quais o capitalismo precisa em escala de Estados e de sociedades inteiras, e não só de tal ou tal estrato social.

[...]

Quijano considera como eurocêntrica a insistência marxista sobre a forma salarial da dominação, na medida em que o proletariado foi sempre minoritário à escala mundial no seio das populações dominadas. Propõe substituir a "teoria eurocêntrica das classes sociais" por uma "teoria histórica de classificação social" [...]. Isto é, o poder é um lugar de conflitos constantes — pelo que penso poder concluir que, como lugar de conflitos, já não tem natureza de classes. É um "poder" capitalista na medida em que o capitalismo explora os trabalhadores de todas as maneiras possíveis e que os mecanismos de dominação para isso - a raça e o gênero — são utilizados de maneira diferenciada no mundo heterogêneo dos trabalhadores.

Embora consideremos que a perspectiva da colonialidade segundo Quijano (2005) oferece uma promissora abordagem para o debate sobre identidade política das trabalhadoras domésticas e seu trânsito por classe, raça e gênero, concordamos com a crítica de Cahen (20I8) ao que chama de "reducionismo" daquele autor ao considerar as formulações de Marx como eurocêntricas, assim como o absolutismo dado à raça em seu esquema conceitual:

Pode-se subalternizar um ser humano com base na nacionalidade, na etni- 


\section{Mariátegui, além de outras subversões}

à ortodoxia, ressaltava a importância dos povos originais, de mulheres vendedoras ambulantes e das empregadas domésticas como sujeitos políticos a ser considerados em um processo revolucionário

cidade, na casta, na religião, no gênero etc., sem que a raça seja o critério dominante. Muitas vezes é uma mistura de tudo isso.

A leitura quijaniana do marxismo também é muito reducionista [...]. Não foi por razão numérica [do proletariado] que Marx desenvolveu a teoria das classes, mas porque teve a formidável capacidade de antevisão de que, com base nas mesmas premissas que ele observava, um novo modo de produção estava crescendo e iria polarizar (e não resumir) a evolução mundial [...] e o modo de produção capitalista [...]. A teoria das classes segundo o europeu Marx não apresenta em si nenhum freio à análise da heterogeneidade de outras formações sociais subalternas [...; ] reconhecer plenamente a heterogeneidade não significa que não haja um modo de produção hegemônico em escala mundial (CAHEN, 20I8, p. 47-48).

Ressalte-se que Quijano (2005) resgata o marxista peruano Mariátegui (I894I930), que já no século XIX combinava gêneros de estudo como a crítica política e a poesia com autores como Nietzsche e Marx. Mariátegui, além de outras subversões à ortodoxia, ressaltava a importância dos povos originais, de mulheres vendedoras ambulantes e das empregadas domésticas como sujeitos políticos a ser considerados em um processo revolucionário. A decolonização do saber (outro conceito básico de autores no campo de estudos sobre colonialidade, decolonialidade e modernidade) pode ser identificada nos trabalhos de Mariátegui, relendo teorias como a de Marx a partir da realidade latino-americana.

Em tais reflexões sobressai o conceito de raça, que em Quijano (2005 e vários outros trabalhos) é estruturante da modernidade, frisando a associação entre formação do construto raça - para ele uma produção dos invasores/colonizadores - e exploração colonial/capitalista, por ideologia sobre o humano (eles, os europeus) e o não humano (os colonizados de pele escura). Quijano frisa a funcionalidade de tal ideologia para o sistema-mundo da divisão social do trabalho racializada. 


\section{I. As trabalhadoras domésticas se fazendo sujeitos na classe: algumas referências da literatura feminista marxista no Brasil ${ }^{6}$}

No Brasil, vários pesquisadores vêm há muito destacando associações entre o trabalho doméstico remunerado - sua valoração ou não valorização - com o trabalho dos negros na casa-grande, no período da escravidão, quando servir aos senhores em afazeres domésticos seria "trabalho de negras". Narrativa comum também em textos de sindicalistas, hoje, como se ilustra com entrevista à sindicalista Creuza Oliveira, realizada em 2018 (CASTRO et al., 20I8), quando se perguntou o que a entrevistada achava que teria mudado nas condições de trabalho e na legislação sobre direito das trabalhadoras domésticas em relação ao Brasil dos anos I990:

Houve sim mudanças de 1990 para cá. Lembre-se de que viemos de trabalhos escravos. Em 1972 conseguimos alguns benefícios. Depois vieram 20 dias de férias, assinatura da carteira de trabalho e contribuição para a previdência social. Em I988, com a Constituição Federal, o salário mínimo, o I3º salário, o aviso prévio, licença-gestante, folga aos domingos de preferência, direito à sindicalização, direito a ir à Justiça. Mas ainda temos empregadas sem carteira assinada, patrões que burlam a lei, ainda temos o assédio sexual e moral que não temos como provar. Mas temos como denunciar. Ainda assim a categoria precisa de ajuda constante. ${ }^{7}$

O trabalho de Saffioti (1978) é uma referência para estudiosos com orientação marxista, com uma crítica feminista estrutural. A autora debate as relações entre trabalho produtivo e improdutivo e analisa o trabalho doméstico como articulação do modo capitalista de produção com formas não capitalistas de trabalho e sua importância na constituição do exército industrial de reserva. A autora buscava uma construção teórica feminista que superasse os limites da teoria marxista na explicação do trabalho doméstico, como constituinte da reprodução do sistema capitalista em países com alto nível de desigualdades sociais, baixos investimentos do Estado em serviços coletivos no campo de cuidados pessoais e exploração das mulheres no contexto do trabalho assalariado, como o Brasil.

Ilustra a ênfase em combinações singulares relacionadas à especificidade do serviço doméstico, quanto a articulações entre classe, raça e gênero, o trabalho de Castro de 1992 (republicado em 20I9). A autora enfatiza, considerando estudo realizado em sindicato de trabalhadoras domésticas, que a identidade de classe e a construção do sujeito político, no caso específico, passam pelo projeto de serem reconhecidas como membros da classe trabalhadora, reelaborando vivências sobre questões

Nesta seção apresentamos de forma sumária texto desenvolvido em partes de Castro et al. (2018).

7 Creuza Maria de Oliveira é uma destacada militante no campo sindical desde 1980. Foi presidente do Sindicato dos Empregados Domésticos da Bahia e da Federação Nacional das Trabalhadoras Domésticas (Fenatrad) e membro da diretoria da Confederacion Latinoamericana de Trabajadoras del Hogar (Conlactraho). Candidatou-se a deputada federal em 2014 pelo Partido Socialista Brasileiro, e em 2012, 2008 e 2006 a vereadora de Salvador, pelo Partido dos Trabalhadores. É hoje secretária-geral da Fenatrad. 
de gênero, de raça, de geração e até de classe, bem como o redimensionamento de significados de constructos do conhecimento feminista, como os de público e privado.

Propõe o conceito de alquimia para a análise das interseções entre as referidas dimensões, ponderando que a estrutura de classe condiciona práticas, mas não as determina, nem limita alianças construídas em nome de interesses de algumas categorias sociais, sendo que, na alquimia destas, nem o conceito de classe se reproduz na íntegra, estando sujeito a reapropriações.

Observa Castro (2019) que múltiplas determinações interativas não se ajustam à perspectiva de essencialidade no tratamento de categorias identitárias e a movimentos sociais específicos, nem ao tradicional modelo de sindicato de classe, sendo que a construção da subjetividade das trabalhadoras domésticas é ainda um processo em aberto, mediante práticas peculiares.

Já Bernardino-Costa (20I5), recorrendo à modelagem teórica de perspectiva decolonial, pensa os sindicatos das trabalhadoras domésticas, desde o seu nascedouro, como um movimento social de resistência à colonialidade do poder e de insistência das trabalhadoras domésticas, ao desempenhar, de um lado, a função de resistência à exploração econômica e à marginalização social, e, de outro, a de constituir-se como uma organização político-trabalhista que, no plano individual, luta pela afirmação da existência de cada profissional, e, no plano coletivo, propõe-se a fundar uma sociedade baseada nos princípios da igualdade e da justiça social.

Para o autor, o movimento das trabalhadoras domésticas, que se revigora nos anos 2000 no Brasil, desvenda a simultaneidade da modernidade e da colonialidade na sociedade contemporânea, revelando que o racismo, não somente na sua dimensão socioeconômica, mas também epistemológica, é uma realidade atual na sociedade brasileira. No seu entender, não se está apenas focando a inclusão das trabalhadoras domésticas através da conquista de direitos e de equiparação constitucional, mas também a discussão acerca dos privilégios de representação e de interesses do patronato, que exclui, oprime e marginaliza aquela categoria profissional (BERNARDINO-COSTA, 20I5).

Em outra seção, mais nos referiremos à sindicalização das trabalhadoras domésticas, após a que se segue, quando se apresenta uma panorâmica do perfil dessas trabalhadoras e vulnerabilizações hoje.

\section{PERFIL DAS TRABALHADORAS DOMÉSTICAS NO BRASIL EM TEMPOS DE PANDEMIA E BARBÁRIE}

O Brasil se destaca como o país com o maior número de trabalhadoras domésticas remuneradas, segundo a OIT, que representam o segundo maior grupamento ocupacional de mulheres no Brasil, ficando atrás apenas do comércio. Em 2018, I4,6\% das mulheres brasileiras ocupadas concentravam-se em atividades remuneradas no trabalho doméstico, sendo essas 5,7 milhões (PINHEIRO et al., 20I9). Estatística que se considera subestimada, já que muitas não se declaram como tais. Muitas não querem "manchar sua carteira de trabalho" (expressão captada em pesquisa de campo) e que aí 
Em que pese a herança colonialista e escravocrata e a conjuntura políticoeconômica adversa, a invisibilidade social das "domésticas" vem diminuindo. Em tempos de pandemia, mais se reconhece sua importância para a reprodução cotidiana, em cuidados. Por outro lado, elas, por seus sindicatos, há algum tempo dizem "não" em alto tom

se as declare como trabalhadoras domésticas. De fato, uma das bandeiras dos sindicatos tem sido a de que a trabalhadora doméstica seja reconhecida e se reconheça como uma trabalhadora que exerce uma profissão digna, não é parte da família empregadora, mas sim parte da classe operária, e como tal com direitos legais e que deve ser respeitada.

Realce-se que essa ideologia da empregada como membro da família empregadora é uma estratégia antiga dos patrões, encontrada em vários países latino-americanos, para as manter isoladas, adversas à sindicalização e sujeitas a maior exploração. Assim como a ideia de que o trabalho doméstico "suja" a carteira de trabalho, dificultando a mobilidade para outros empregos (CHANEY; CASTRO, 1993).

O trabalho doméstico é um dos mais importantes para as mulheres negras: em 20I8, nessa ocupação estavam 3,9 milhões de mulheres negras - 63\% do total de trabalhadores(as) domésticos(as).

Vários autores vêm há muito destacando a não valorização do trabalho doméstico por sua interação entre classe, gênero e raça, processo que estrutura desigualdades sociais objetivas e discriminações. É tido como trabalho de mulher - menos de I\% dos trabalhadores domésticos em 2018 seriam homens; era e é trabalho para pobres, e era o trabalho dos negros na casa-grande, conjugando portanto tal ocupação os efeitos de cultura patriarcal, racismo estrutural, falta de oportunidades de trabalho para os mais pobres e configuração de um sistema de classes sociais.

A associação entre serviço doméstico e gênero é mais um elemento estrutural e se traduz não somente em sua desvalorização social ou banalização, como "coisa de mulher", legitimando-se na histórica divisão sexual do trabalho, mas também pela invisibilidade do custo de reprodução, pois as trabalhadoras domésticas, em duplas jornadas de trabalho, cuidam das famílias empregadoras e das suas. Contudo, insiste-se, é mais na literatura sobre trabalho doméstico de autoria feminista que propriamente 
em narrativas de sindicalistas que gênero e patriarcado são destacados como fatores estruturantes a serem endereçados.

O serviço doméstico é básico para a reprodução social em uma sociedade como a brasileira, em que o Estado neoliberal cada vez mais privatiza serviços, que não dispõe de um sistema de segurança social, serviços públicos de cuidados, como creches e escolas em tempo integral, e que estimula a ideologia individualista, que desumaniza o outro, considerado inferior.

Muitas mulheres trabalham no mercado porque contam com outra em suas casas, cuidando de suas famílias, além de lhes garantir mais tempo livre, mais conforto, melhor qualidade de vida.

Em tempos de isolamento social pela pandemia de coronavírus, é comum certo reconhecimento tardio pelas patroas do valor do trabalho das "domésticas", o que não corresponde a apoio para a sobrevivência destas, o que mais se comenta em outra parte deste artigo.

Apesar das duras condições de trabalho, em especial pela maior exigência dos patrões quanto à intensidade do trabalho, dupla jornada e deslocamentos casa-trabalho em condições ruins, devido ao período de crise econômica, as diaristas declaram que gostariam de trabalhar mais horas, segundo dados da pesquisa por amostra domiciliar em 20I8. Por essa fonte se tem que, entre as trabalhadoras domésticas mensalistas, apenas I0\% desejavam alocar mais horas em trabalho pago do que atualmente alocam. Entre as diaristas, contudo, essa proporção saltava para I/3 das informantes. E se registraram desigualdades raciais: $27 \%$ das diaristas brancas gostariam de trabalhar mais horas; já 35\% das diaristas identificadas como não brancas indicaram tal vontade, o que pode sugerir maiores dificuldades econômicas das mulheres negras.

Outro indicador de precariedade no serviço doméstico se refere a horas trabalhadas. Para 2018 tem-se que I/4 das trabalhadoras domésticas exercia jornadas superiores a 40 horas semanais, sendo que $12 \%$ ultrapassavam as 44 horas semanais previstas em lei. Entre as mensalistas, essa proporção alcançava aproximadamente I6\%. Ou seja, quase 2 em cada Io trabalhadoras que atuavam como mensalistas trabalhavam com jornadas superiores à estabelecida por lei - "a lei complementar $\mathrm{n}^{\circ}$ I50/20I5 só permite jornadas de trabalho de até 44 horas semanais ou 8 horas diárias, sendo possível a realização de, no máximo, 2 horas extras por dia, as quais devem ser remuneradas com valor 50\% superior à hora normal" (PINHEIRO et al., 20I9).

Vem se evidenciando o envelhecimento das trabalhadoras domésticas, o que se deve ao aumento da escolaridade das jovens mulheres, que buscam, assim, novas possibilidades de inserção no mercado de trabalho:

A proporção de mulheres idosas (com mais de 60 anos) cresceu de forma muito mais intensa para as trabalhadoras domésticas do que para as mulheres ocupadas de forma geral. [...] Entre 1995 e 2018, o peso das mais velhas (no serviço doméstico) mais do que dobrou, saltando de $3 \%$ para mais de $7 \%$, com um pico de $8 \%$ em 2017 (PINHEIRO et al., 20I9). 
Contudo, em período de crise econômica o serviço doméstico tende a crescer, e as jovens, a voltarem a tal emprego.

Vem crescendo a representação das trabalhadoras diaristas. Elas atuam em mais de um domicílio, comumente sem vínculo empregatício com qualquer um deles. Seu crescimento está afim com o movimento de informalização dos trabalhadores. Os anos recentes de crise econômica parecem ter tido como efeito a migração da categoria de assalariada ou mensalista para a de trabalho por dia, como diarista, mais desprotegida e menos custosa para o empregador, e, ainda, sem a proteção de uma carteira de trabalho assinada.

Os últimos dados, de 2018 , mostram que cerca de $30 \%$ das diaristas prestavam serviços em mais de um domicílio. E já respondiam por $44 \%$ da categoria, o que equivalia a 2,5 milhões de mulheres. Por lei, elas só podem trabalhar até o máximo de 2 dias por semana na mesma casa, mas muitas trabalham em 3 ou 4 casas por semana, sem os direitos que conseguiram as assalariadas e geralmente com jornadas de mais de 40 horas, contabilizando trabalho e deslocamentos.

Os sindicatos de trabalhadoras domésticas têm desenvolvido campanhas para mudar a legislação para que as diaristas contem com proteção trabalhista, o que estaria de acordo com a convenção I89 da OIT sobre trabalho doméstico e emprego decente (OIT, 20I8) — convenção de 20II, mas só ratificada pelo Brasil em 2018.

Os sindicatos desenvolvem campanhas direcionadas às trabalhadoras para que elas se inscrevam no sistema de previdência como autônomas, para terem alguma garantia. Note-se que as diaristas não estão vinculadas ao sistema de previdência social, a não ser que contribuam de maneira individual, e assim detêm menos direitos trabalhistas, não podendo contar com licenças remuneradas em caso de acidente de trabalho, maternidade e problemas de saúde, entre outros. Tampouco têm direito ao Fundo de Garantia do Tempo de Serviço (FGTS), às férias remuneradas e ao recebimento de $13^{\circ}$ salário, por exemplo. Mas é muito difícil que a diarista se inscreva no sistema de previdência como autônoma, pois tal medida geralmente significaria ter de arcar com todos os custos da inscrição, mensalmente, o que hoje seria cerca de II\% de um salário mínimo, o que muitas diaristas não fazem por mês.

Apesar de a legislação proibir que se pague menos que um salário mínimo para as trabalhadoras mensalistas, muitas recebem menos, principalmente se sem carteira assinada. Segundo os dados da pesquisa por amostra domiciliar de 2018 (PINHEIRO et al., 2019):

O rendimento no emprego doméstico alcançou 92\% do salário mínimo. Entretanto, a renda média das trabalhadoras domésticas ainda corresponde somente a $47 \%$ da renda das mulheres ocupadas. Quanto à renda, há também importantes desigualdades entre mensalistas e diaristas, trabalhadoras com e sem carteira, brancas e negras, e de acordo com a região. O grupo com maior renda média são as mensalistas brancas com carteira assinada. 
A maior vulnerabilidade social das diaristas mais se afirma em período de pandemia, pois muitas perdem o emprego, e a campanha dos sindicatos apelando aos patrões para que paguem a diária mesmo que as diaristas fiquem, como deveriam, em casa, em isolamento social, não vem encontrando resposta favorável ampla, segundo sindicalistas.

É emblemático um caso que teve repercussão internacional, o de ter sido uma trabalhadora doméstica diarista (d. Cleonice), uma das primeiras vítimas do coronavírus no Brasil, contaminada pela patroa que teria chegado da Itália. Isso em 26 de fevereiro de 2020. Em 22 de abril, a BBC News noticiou:

Pesquisa realizada pelo Instituto Locomotiva entre os dias I4 e i5 de abril deste ano destaca que $39 \%$ dos patrões de diaristas e $48 \%$ dos de mensalistas declararam que suas funcionárias estão mais protegidas contra o novo coronavírus: estão em casa, mas recebendo o pagamento normalmente para cumprir o distanciamento social requerido contra a doença.

Os dados mostram um retrato duplamente preocupante, na visão do sócio e presidente do Instituto Locomotiva, Renato Meirelles: indicam que, além das muitas trabalhadoras que estão sem renda e sem condição de atender às necessidades básicas de suas famílias, há um outro contingente grande de faxineiras que está trabalhando normalmente e se deslocando por grandes distâncias pela cidade e pelos transportes públicos, sem poder atender às recomendações da Organização Mundial de Saúde (OMS) de ficar em casa para reduzir a circulação do vírus ().

O envelhecimento da categoria alerta sobre a probabilidade de muitas estarem sobrerrepresentadas em grupos de risco para o coronavírus. O que se agrava por outras dimensões, como a pobreza dos lugares onde vivem, as relações sociais de trabalho, em muitos casos de subserviência e em isolamento, e por envolver deslocamento por transporte público, que no Brasil, mesmo nas grandes metrópoles, é precário e costuma ser insuficiente para a demanda, além do contato direto com pessoas das famílias às quais prestam serviços, e em muitos casos, como no de cuidadoras de idosos, serem encarregadas das compras de mercado, ou seja, encontrando-se mais expostas a contágios.

O cenário histórico de desigualdades sociais é reforçado por um governo que vem cortando conquistas dos trabalhadores e marginalizando os serviços de saúde pública e de segurança social. Note-se que, mesmo antes da pandemia de coronavírus, a informalidade e a precariedade eram parte do quadro de desigualdades crescentes. O desemprego no Brasil teria aumentado em II,6\% no trimestre encerrado em fevereiro de 2020, o último antes de a pandemia se espalhar pelo país, segundo dados divulgados pelo IBGE, abarcando I2,3 milhões de desempregados. Mas em 2019 havia no Brasil 206 bilionários, com uma fortuna total de R \$ I.205,8 bilhões (I7,7\% do PIB brasileiro), o que bem demonstra que, mais que pobreza, estruturalmente imperam desigualdades sociais e de várias ordens. 


\section{SindICALIZACÃO NO SERVICOO DOMÉSTICO}

Em 1936 foi fundada a Associação Profissional dos Empregados Domésticos de Santos (SP) por Laudelina de Campos Melo. Tal entidade tinha como objetivo a conquista do status jurídico de sindicato, uma vez que assim poderia negociar com o Estado o reconhecimento jurídico da categoria e, consequentemente, direitos trabalhistas (BERNARDINO-COSTA, 20I5).

Entre os anos 1960 e I980, observa-se uma fase do movimento das trabalhadoras domésticas com dimensão nacional, na qual predomina a busca por reconhecimento como integrantes da classe trabalhadora, bem como o desenvolvimento de articulações da categoria com o movimento negro, o movimento de mulheres, a Igreja Católica e as representações de religiões de matrizes africanas.

A partir dos anos 1980 se evidenciou um período marcado por uma intensa mobilização das trabalhadoras domésticas, com o objetivo de inserir os direitos trabalhistas da categoria no debate sobre a redemocratização do país, o que resultou na inserção de tais direitos na Constituição de I988, ainda que parcialmente, pois não ocorreu o reconhecimento das entidades sindicais. $\mathrm{Na} \mathrm{CRFB} / 88$, cuja elaboração envolveu milhares de mulheres e homens que se organizaram para a ampliação e conquistas de direitos, a categoria das trabalhadoras domésticas ficou em desvantagem, pois, apesar de ser considerada a Constituição mais avançada da América Latina, garantiu para essa categoria apenas 13 das 33 conquistas das demais categorias de trabalhadores.

É justamente no período I995-20Io que, no plano de organização coletiva, o reconhecimento das entidades sindicais se torna uma bandeira de luta do movimento das trabalhadoras domésticas. Em 1994, a categoria cria seu conselho nacional, e, em 25 de maio de 1997, funda a Federação Nacional das Trabalhadoras Domésticas (Fenatrad).

No entender de Bernardino-Costa (2015), ao longo de suas histórias, as diversas organizações das trabalhadoras domésticas têm desempenhado, por um lado, a função de resistência à exploração econômica e à marginalização social, e, por outro lado, têm sido organizações político-trabalhistas que, no plano individual, lutam pela afirmação da existência humana de cada trabalhadora doméstica e, no plano coletivo, se propõem fundar uma sociedade baseada, por exemplo, nos princípios da igualdade, justiça social e dignidade.

A Fenatrad, juntamente com a Conlactraho (Confederación Latinoamericana y del Caribe de Trabajadoras del Hogar), teve uma ativa participação nas conferências da OIT (Organização Internacional do Trabalho) nos anos de 2010 e 20II, provocando, com outros atores, a aprovação da convenção I89 da OIT (sobre trabalho decente) e o processo que no Brasil, após intensa mobilização junto com a sociedade civil e política e dois anos de discussão no plano legislativo, levou à aprovação da PEC (proposta de emenda constitucional) $n^{\circ} 72 / 2013$ - e sua posterior regulamentação pela lei complementar no $150 / 2015$. 
Na página $w e b$ da Fenatrad, há indicações da sua orientação por se afirmar como uma entidade de classe, e de como na narrativa sindical raça e classe se conjugam, realimentando uma identidade una, não segmentada; bem como se evidencia a estratégia que caracteriza os sindicatos da categoria, a busca por alianças com outras organizações, como as de trabalhadores, do movimento negro e do movimento feminista:

A Federação Nacional das Trabalhadoras Domésticas (Fenatrad) é uma associação formada por 22 sindicatos e mais uma associação. Ela representa uma categoria formada por, aproximadamente, 7,2 milhões de trabalhadores e trabalhadoras domésticas.

As organizações filiadas à federação estão presentes em I3 estados brasileiros. Essa união entre as entidades é chamada de "organização de classe". Essa organização é importante para que as mulheres e homens que desenvolvem trabalho doméstico tenham os mesmos direitos que outros trabalhadores: carteira assinada, férias remuneradas, FGTS, dentre outros.

As mulheres são maioria no trabalho doméstico. Por isso, a Fenatrad usa mais frequentemente o termo "trabalhadoras domésticas" em seus documentos e material informativo. A Fenatrad caminha ao lado de outros movimentos e instituições que defendem a igualdade dos direitos para as mulheres e combatem o preconceito contra elas.

A maioria das trabalhadoras e trabalhadores domésticos é formada por negras e negros. Daí que os sindicatos e as associações mantêm um diálogo muito forte com as organizações do movimento negro. Essas alianças são muito importantes para a troca de experiências e desenvolvimento de ações que ajudam todo mundo (FENATRAD, 2016, destaques nossos).

A Fenatrad tem tido relevante participação na estruturação e trabalhos da Conlactraho, entidade que reúne sindicatos e associações de trabalhadores domésticos de 26 países da América Latina, tendo sido fundada em 1983. Tal participação tem permitido à categoria uma articulação internacional e nacional mais qualificada e uma maior visibilidade para o debate sobre a temática, por meio de estudos em conjunto e trocas de experiências em nível latino-americano. As representantes brasileiras naquela confederação em 20II tiveram ativa participação na OIT para a modelação da convenção I89.

Tanto a Fenatrad como os diversos sindicatos de trabalhadoras domésticas em diferentes estados do Brasil muito recorrem a alianças com centrais sindicais, entidades do movimento negro e organizações de corte feminista para campanhas e ações conjuntas.

Tal estratégia vem sendo acionada para garantir alguma proteção às trabalhadoras domésticas em tempos de pandemia, ao mesmo tempo que amplia a visibilidade social das organizações sindicais. Nessa linha emitem-se manifestos e notas amplamente divulgados em redes digitais, como por exemplo a nota de repúdio à 
medida do Governo do Pará (estado e município), em maio, que incluiu o serviço doméstico na lista dos serviços essenciais, assim estimulando a circulação das trabalhadoras. A nota da Fenatrad recebeu o apoio de distintas entidades, como a Central Única dos Trabalhadores (CUT), a Confederação dos Trabalhadores no Comércio e Serviço (Contracs), a Themis - Gênero, Justiça e Direitos Humanos,o Centro de Estudo e Defesa do Negro do Pará (Cedenpa) e a União Brasileira de Mulheres (UBM). $\mathrm{O}$ estado anulou a medida posteriormente.

Nessa nota da Fenatrad, mais uma ilustração de que se prioriza um discurso que evoca uma herança escravocrata a ser eliminada:

Nós sempre lutamos por valorização e a sociedade nunca quis reconhecer a importância do serviço doméstico. Aí, neste momento de pandemia, a casa-grande, que está em quarentena, não quer se dar ao trabalho de fazer as próprias tarefas domésticas. Colocar o serviço doméstico como essencial de forma generalizada é uma crueldade. As trabalhadoras domésticas também têm famílias", disse Luiza Batista, presidenta da Fenatrad (FENATRAD).

Muito noticiado, inclusive pela imprensa internacional, o que também indica que a mobilização do serviço doméstico organizado congrega atores diversificados, foi o abaixo-assinado dos filhos de trabalhadoras domésticas sobre os riscos de suas mães em tempos de pandemia. Com a morte de Cleonice, primeira vítima do coronavírus no Brasil, filhos e familiares de trabalhadoras domésticas lançaram um abaixo-assinado on-line, "Quarentena remunerada já para domésticas e diaristas!", com depoimentos dos filhos, comumente exercendo outras profissões que não o trabalho doméstico, e muitos com diploma de nível superior. $\mathrm{O}$ abaixo-assinado recebeu mais de 25 mil assinaturas (até 20 de abril):

Ao constatarmos que nossas familiares que são empregadas domésticas e diaristas continuam trabalhando normalmente, salientamos a emergência de atender à quarentena estipulada pelas autoridades e reivindicamos a dispensa remunerada das empregadas domésticas e diaristas pelos empregadores para que, assim, cumpram com as exigências de precaução no combate à propagação contagiosa da covid-I9.

$[\ldots]$

"Minha mãe trabalha desde os 6 anos de idade como doméstica e diarista, e a vi muitas vezes ir trabalhar doente para manter seus compromissos. Mesmo falando sobre os riscos do corona, ela não tem como faltar, com risco de ser demitida. [...] (Marcelo Rocha — Mauá/SP)" (PELA VIDA DE NOSSAS MÃES, 2020).

Os sindicatos se desdobram em funções clássicas de luta por direitos em instâncias diversas, pressionando os governos, a eles resistindo e se dedicando à tradução das normas governamentais, para bem interpretar e evitar possíveis danos a direitos, inclusive acompanhando a dinâmica recente de medidas que afetam os trabalhado- 
res, contando, em muitos casos, com o apoio de agências relacionadas ao movimento feminista, como se documenta a seguir:

O governo federal publicou no dia 22, domingo, a medida provisória $\mathrm{n}^{\circ}$ 927 de 2020, que flexibiliza ainda mais as relações de trabalho. O texto autorizava, por meio do artigo i8, que os contratos de trabalho fossem suspensos por até quatro meses sem necessidade de acordo ou convenção coletiva. Amplamente criticado por centrais sindicais, instituições como a Associação Nacional dos Magistrados da Justiça do Trabalho (Anamatra) e pela população nas redes sociais, o artigo foi revogado em uma outra medida provisória, a MP no 928 de 2020, publicada no dia 23, segunda-feira. No entanto, várias outras mudanças da MP no 927 seguem valendo. Um dos mais problemáticos é o artigo $2^{\circ}$, que autoriza os empregadores a firmarem, durante esse estado de calamidade pública, acordos individuais com os trabalhadores, que terão "preponderância sobre os demais instrumentos normativos legais e negociais, respeitados os limites estabelecidos na Constituição", segundo a MP. [...]

$[\ldots]$

[Considera-se que o fato de as trabalhadoras domésticas trabalharem isoladas] fará com que a MP no 927 seja mais cruel com a categoria. Para quem atua em uma empresa com mais de um funcionário, por exemplo, os trabalhadores podem conversar entre eles sobre os contratos e possíveis reivindicações.

Além da MP, que permite acordos apenas com os direitos constitucionais, os contratos entre as trabalhadoras domésticas e os empregados são individuais, sem participação dos sindicatos, o que as deixa mais vulneráveis às precarizações. [...]

[...]

Por isso, para orientar trabalhadoras domésticas sobre direitos trabalhistas, a Themis mantém atualizado o aplicativo Laudelina, que também permite a formação de rede. "Nesse momento, é muito importante que essas profissionais se mantenham em coletividade e procurem espaços onde as inquietações delas são ouvidas, como o sindicato do território, a Fenatrad e o Laudelina", completa a assessora jurídica [da Themis] (COSTA, 2020). ${ }^{8}$

Em que pese o trabalho ativo das agências sindicais, pesquisa do Ipea de 20 II (CASTRO et al., 20I8) revela que tão somente I8\% do total das trabalhadoras domésticas no ano de 2009 estavam sindicalizadas. Tal baixa taxa de sindicalização se associaria a um conjunto de dificuldades típicas das especificidades do trabalho doméstico, como o isolamento, mas também ao fato de esse ser um trabalho desvalorizado e precário.

8 Oplicativo Laudelina foi desenvolvido pela organização Themis em parceria com a Fenatrad, especificando direitos das trabalhadoras e dados dos sindicatos para contatos. Ver: <https://fenatrad. org.br>. Acesso em: 2 maio 2020. 
Insiste-se: a situação de desproteção é grave para o conjunto das trabalhadoras domésticas, independentemente de sua cor ou raça e da região de residência. Contudo, para alguns grupos, a vulnerabilização é ainda mais intensa - em 20I8, 29,3\% das trabalhadoras domésticas negras e $24,6 \%$ das brancas trabalhavam sem carteira de trabalho assinada; muitas laboravam 58 horas semanais, com remuneração média abaixo do salário mínimo estipulado por lei.

Ou seja, com a ambiência de perda de direitos trabalhistas, a Emenda Constitucional das Domésticas vem sendo solapada pelo governo Bolsonaro. Não se fiscaliza seu cumprimento, e com grande probabilidade estará se ampliando o contingente de trabalhadoras domésticas em situação de informalidade.

\section{CONSIDERAÇ̃̃ES FINAIS}

Em que pese a herança colonialista e escravocrata e a conjuntura político-econômica adversa, a invisibilidade social das "domésticas" vem diminuindo. Em tempos de pandemia, mais se reconhece sua importância para a reprodução cotidiana, em cuidados. Por outro lado, elas, por seus sindicatos, há algum tempo dizem "não" em alto tom.

A organização das trabalhadoras domésticas no Brasil, ao nível local em sindicatos, assim como ao nível nacional em uma federação, e ao nível internacional em uma confederação, é hoje uma realidade pujante, ainda que tais entidades congreguem, em termos sindicais, quando muito, menos de $20 \%$ do total de trabalhadores do setor.

As organizações de trabalhadoras domésticas contabilizam vitórias como a legislação por direitos iguais aos de outros trabalhadores (Emenda Constitucional das Domésticas). São reconhecidas como representantes da classe, inclusive na imprensa, e vêm tendo um singular papel, desde a luta por proteção contra o coronavírus, diretamente, por meio de pressões sobre o Estado, como, principalmente, ampliando sua rede de alianças tanto com entidades de classe como com movimentos sociais e agências internacionais.

Embora prezem parcerias e contem com a colaboração de movimentos com forte presença política, como o movimento negro e o movimento feminista, e em especial de organizações de trabalhadores, como a CUT, além do apoio de alguns parlamentares de partidos de esquerda, as organizações de trabalhadoras domésticas primam pela autonomia e singularidade na forma como combinam raça, gênero e classe. Ao mesmo tempo que dialogam com aqueles movimentos e têm presença marcante em comemorações como o Oito de Março e em manifestações contra um governo que se caracteriza por ser contra os trabalhadores e as conquistas das mulheres e dos negros, os sindicatos mesclam o formato de cuidados com o de empenho na luta por direitos, e recorrem a um repertório próprio em seus documentos, como reconhecer e repelir a herança de relações escravocratas e insistir em temas de direito à igualdade e contra violências no campo de gênero. Contudo, não se envolvem com pautas libertárias, como aquelas da área de direitos sexuais e reprodutivos - por exemplo, 


\section{Um projeto mais radical por outro tipo de sociedade não comporta o trabalho doméstico remunerado, e as críticas de marxistas clássicos à "escravização do trabalho doméstico", como à solidão que o caracteriza, obstaculizando mobilização coletiva, muito valem para o serviço doméstico}

sexualidades, corpo e aborto (CASTRO, 20I9; CASTRO et al., 20I8) —, já que muitas trabalhadoras domésticas, inclusive líderes no setor, são ligadas a religiões que não aceitariam aquelas pautas.

Dedicam-se ao acolhimento das iguais, cuidado pelas idosas e diaristas, as mais vulnerabilizadas. $\mathrm{O}$ ambiente dos sindicatos é de acolhimento, o que se combina com pressões a deputados, campanhas públicas e redes de resistência com outros organismos de classe.

Os direitos, como os adquiridos em 20I5, vêm sendo ameaçados, e se alerta que hoje, em 2020, 70\% das trabalhadoras domésticas estão na informalidade, ou seja, sem garantias trabalhistas.

Com tal quadro estrutural e conjuntural, as organizações sindicais de trabalhadoras domésticas vêm pressionando o governo por medidas emergenciais como proteção do contrato de trabalho e representação das trabalhadoras, em especial diaristas, entre os beneficiários do fundo emergencial para autônomos, no setor informal e desempregados, que o governo acionou. Por outro lado, têm desenvolvido campanhas para apelar ao senso de justiça dos patrões, para que eles garantam que as trabalhadoras possam se proteger com isolamento social e serem remuneradas nesse período, se diaristas, ou por acordos contratuais. Desenvolvem árduo trabalho personalizado de traduzir a linguagem burocrática das medidas legais sobre contratação, crescendo a procura por meios digitais e por telefone.

O sindicalismo no serviço doméstico vem se embasando em práticas modeladas em relações sociais de assalariamento ou emprego, nas quais o patrão é comumente uma mulher - o que mais complica avançar em agendas feministas - e em que as fronteiras entre o público e o privado são tênues. Relações sociais em que gênero, classe e raça são ressignificadas, considerando a diversidade de casos que lhe chegam.

Aproximam-se de outros "iguais", sindicatos de trabalhadores de outras categorias. Mas estes, hoje não tão preconceituosos diante de profissionais que não eram consideradas parte da classe, ainda têm dificuldade em compreender como unificar 
ações de classe e ao mesmo tempo respeitar um processo identitário que lhes é estranho, pautado em relações sociais que transitam entre o público e o privado, formas capitalistas e não plenamente tais.

Ao perguntar à líder sindical Creuza Maria Oliveira, em 1992 (CASTRO, 2019), "qual sua raça?”, obtive esta resposta: “Eu sou uma mulher negra, trabalhadora doméstica.” Repeti a questão e ela insistiu na resposta, adiantando pistas do seu porquê: "Não me vejo só mulher, só negra, só trabalhadora doméstica, e é assim que eu vivo a minha cor."

Gayle Rubin, uma das primeiras autoras a recorrer ao conceito de gênero, embasa-se em Marx para enfatizar a propriedade compreensiva do constructo relações sociais: Marx, certa vez, questionou: "O que é um escravo negro? Um homem da raça negra. Uma explicação vale tanto quanto a outra. Um negro é um negro. Só em determinadas relações é que ele se torna escravo. Uma máquina de fiar algodão é uma máquina de fiar algodão. Apenas em determinadas relações ela se torna capital. Fora dessas relações, ela já não é mais capital, assim como o ouro em si não é dinheiro, nem o açúcar é igual ao preço do açúcar" (MARX, I97I, p. 28). Poderíamos parafrasear: O que é uma mulher domesticada? Uma fêmea da espécie. Uma explicação vale tanto quanto a outra. Uma mulher é uma mulher. Ela só se transforma em mulher do lar, em esposa, em escrava, em coelhinha da Playboy, em prostituta, em um ditafone humano, dentro de determinadas relações (RUBIN, I975, p. I58, tradução nossa).

E quando as relações sociais são diversas e misturadas, mesmo sob a égide de uma estrutura de classe?

Um projeto mais radical por outro tipo de sociedade não comporta o trabalho doméstico remunerado, e as críticas de marxistas clássicos à "escravização do trabalho doméstico", como à solidão que o caracteriza, obstaculizando mobilização coletiva, muito valem para o serviço doméstico. Mas o trabalho doméstico organizado, em tempos de capitalismo, em especial nas formas de barbárie que vem assumindo, briga por relações sociais de trabalho pautadas por direitos como os de outros trabalhadores e contra um Estado, ou melhor, um governo antagônico aos trabalhadores. E briga se afirmando, como nos sugere a expressão da sindicalista Creuza Oliveira, antes citada, como "mulher-negra-trabalhadora doméstica". Ou seja, combinando categorias que, como observou Mariátegui, podem vir a produzir um sujeito revolucionário.

\footnotetext{
* PhD em Sociologia. Professora visitante do Instituto de Filosofia e Ciências Sociais (IFCS) -Programa de Pós-Graduação em Sociologia e Antropologia (PPGSA) da Universidade Federal do Rio de Janeiro (UFRJ) e pesquisadora da Facultad Latinoamericana de Ciencias Sociales (Flacso-Brasil).

E-mail: castromg@uol.com.br
}

Texto recebido em maio de 2020; aprovado em junho de 2020. 
ALBARRACÍN, Jesus. O trabalho doméstico e a lei do valor. In: FARIA, Nalu; NOBRE, Miriam (Org.). O trabalho das mulheres: tendências contraditórias. São Paulo: SOF, 1999.

ANDRADE, Joana El-Jaick. O feminismo marxista e a demanda pela socialização do trabalho doméstico e do cuidado com as crianças. Revista Brasileira de Ciência Política, Brasília, n. 18, set./dez. 2015. Disponível em: $\leq$ www.scielo.br/scielo.php?script=sci arttext\&pid=S0103-33522015000400265> . Acesso em: 2 abr. 2020.

BERNARDINO-COSTA, Joaze. Saberes subalternos e decolonialidade: os sindicatos das trabalhadoras domésticas do Brasil. Brasília: Editora UnB, 2015.

CAHEN, Michel. O que pode ser e o que não pode ser a colonialidade: para uma aproximação pós-pós-colonial da subalternidade. In: ; BRAGA, Ruy (Org.). Para além do pós(-)colonial. São Paulo: Alameda, 2018. p. 31-74.

CASTRO, Mary Garcia. Desafios ao marxismo e ao feminismo emancipacionista em tempos de barbárie neoliberal. In: MARTUSCELLI, Danilo Enrico (Org.). Os desafios do feminismo marxista na atualidade. Chapecó: Marxismo 21, 2020. p. 139-154.

Mulheres sindicalizadas: classe, gênero, raça e geração na produção de novos sujeitos políticos: um estudo de caso sobre o serviço doméstico. In: HOLLANDA, Heloisa Buarque de. Pensamento feminista brasileiro: formação e contexto. Rio de Janeiro: Bazar do Tempo, 2019. p. 213-236.

; SILVA, João Victor Marques da; SOUZA, Maria das Graças Neves de. Entre mudanças e persistências na história: trabalhadoras domésticas no Brasil contemporâneo. In: CALAZANS, Márcia Esteves de; CASTRO, Mary Garcia; PIÑEIRO, Emília (Org.). América Latina: corpos, trânsitos e resistências. Porto Alegre: Editora Fi, 2018. v. 2, p. 153-184. Disponível em: <www.editorafi.org/411americalatina>. Acesso em: 29 jun. 2020.

CHANEY, Elsa; CASTRO, Mary Garcia. Muchacha cachifa criada empleada, empregadinha sirvienta y... más nada: trabajadoras del hogar en América Latina y el Caribe. Caracas: Nueva Sociedad, 1993.

CORREIA, Marcus Orione Gonçalves; BIONDI, Pablo. Uma leitura marxista do trabalho doméstico. Revista LTR, São Paulo, v. 75, p. 311-317, 2011. Disponível em: <https:// edisciplinas.usp.br/pluginfile.php/346001/mod_resource/content/0/uma-leitura-marxista-do-trabalho-domestico.pdf>. Acesso em: 3 maio 2020.

COSTA, Fernanda da. Morte de trabalhadora doméstica por coronavírus escancara falta de políticas para proteger a classe. Jornal da Universidade (UFRGS), Porto Alegre, 26 mar. 2020. Disponível em: <www.ufrgs.br/jornal/morte-de-trabalhadora-domestica-por-coronavirus-escancara-falta-de-politicas-para-proteger-a-classe>. Acesso em: 5 abr. 2020.

COULSON, Margaret; MAGAŠ, Branka; WAINWRIGHT, Hilary. The housewife and her labour under capitalism: a critique. New Left Review, Londres, n. 89, p. 59, 1975.

FEDERICl, Silvia. Calibã e a bruxa: mulheres, corpo e acumulação primitiva. São Paulo: Elefante, 2017. 
O ponto zero da revolução: trabalho doméstico, reprodução e luta feminista. São Paulo: Elefante, 2019.

FENATRAD. Institucional: união para conquistar direitos. Brasília, 2016. Disponível em: $<$ https://fenatrad.org.br/institucional>. Acesso em: 1 maio 2020.

HOLLANDA, Heloisa Buarque de (Org.). Pensamento feminista hoje: perspectivas decoloniais. Rio de Janeiro: Bazar do Tempo, 2020.

KERGOAT, Danièle. Dinâmica e consubstancialidade das relações sociais. Novos Estudos Cebrap, São Paulo, n. 86, mar. 2010. Disponível em: <http://dx.doi.org/10.1590/S010133002010000100005>. Acesso em: 3 nov. 2019.

MENDES, Isabella Oliveira. O trabalho doméstico feminino e a produção capitalista: um debate na New Left Review. Multiface, Belo Horizonte, v. 5, n. 2, p. 31-45, 2017. Disponível em: <https://revistas.face.ufmg.br/index.php/multiface/article/view/4127>. Acesso em: 3 maio 2020.

OIT. Brasil ratifica Convenção 189 da OIT sobre trabalho doméstico. Brasília, 1 fev. 2018. Disponível em: <www.ilo.org/brasilia/noticias/WCMS_616754/lang--pt/index. htm>. Acesso em: 30 jun. 2020.

PELA VIDA DE NOSSAS MÃES. Manifesto das filhas e dos filhos de empregadas(os) domésticas(os) e diaristas. Mar. 2020. Disponível em: <https://drive.google.com/file/ d/1Xo5dcasbWAsk6w00qliWU2exHbq-5ysw/view>. Acesso em: 7 maio 2020.

PINHEIRO, Luana et al. Os desafios do passado no trabalho doméstico do século XXI: reflexões para o caso brasileiro a partir dos dados da Pnad Contínua. Texto para Discussão 2528. Brasília: Ipea, nov. 2019. Disponível em: <https://www.ipea.gov.br/portal/index. php?option $=$ com_content\&view $=$ article\&id $=35231 \&$ catid $=419 \&$ Itemid $=444>$. Acesso em: 12 abr. 2020.

QUIJANO, Aníbal. Colonialidade do poder, eurocentrismo e América Latina. In: LANDER, Edgardo (Org.). A colonialidade do saber: eurocentrismo e ciências sociais - Perspectivas latino-americanas. Buenos Aires: Consejo Latinoamericano de Ciencias Sociales, 2005.

RUBIN, Gayle. The traffic in women: notes on the "political economy" of sex. In: REITER, Rayna (Ed.). Toward an anthropology of women. Nova York: Monthly View Press, 1975. p. 157-210.

SAFFIOTI, Heleieth. Emprego doméstico e capitalismo. Petrópolis: Vozes, 1978.

SECCOMBE, Wally. Domestic labour: reply to critics. New Left Review, Londres, n. 94, p. $85,1975$.

. The housewife and her labour under capitalism. New Left Review, Londres, n.

83, p. 3, 1974. 